\title{
E3 Ubiquitin-Protein Ligase UBR5
}

National Cancer Institute

\section{Source}

National Cancer Institute. E3 Ubiquitin-Protein Ligase UBR5. NCI Thesaurus. Code

C111930.

E3 ubiquitin-protein ligase UBR5 (2799 aa, $209 \mathrm{kDa}$ ) is encoded by the human UBR5 gene. This protein plays a role in the promotion of both protein ubiquitination and protein catabolism. 